\title{
Loading capacity of dynamic knee spacers: a comparison between hand-moulded and COPAL spacers
}

\author{
Sook-Yee Chong ${ }^{1,2^{*}}$ DD, Lu Shen ${ }^{3}$ and Sandra Frantz ${ }^{1}$
}

\begin{abstract}
Background: The two-stage revision protocol represents the current gold standard for treating infected total knee replacement implants. Allowing early mobility with weight-bearing between staged procedures will enable early restoration to knee function. So, the mechanical performance of knee spacers is a key issue. Commercially available moulds are often used as they are easy to prepare and produce smoother surfaces of the articulating parts. However, they are costly, and only for single use. A cost-effective alternative is the surgeon-made hand-moulded spacers. In this study, we wanted to determine how the hand-moulded spacers will compare biomechanically with the commercially available COPAL spacers.

Methods: Seven cadaveric knees were implanted with knee spacers fabricated using COPAL knee moulds. The same surgeon implanted eight cadaveric knees with hand-moulded spacers. In the first test protocol, an axial load was applied at $200 \mathrm{~mm} / \mathrm{min}$ till failure. In the second test protocol, the knees were cyclically loaded in five steps of 1000 cycles each from 30-400 N, 30-600 N, 30-800 N, 30-1000 N, 30-1200 N at $1.5 \mathrm{~Hz}$.

Results: COPAL knee spacers demonstrated a maximum load and mean stiffness of $5202( \pm 486.9) \mathrm{N}$ and $1098( \pm 201.5) \mathrm{N} / \mathrm{mm}$ respectively. The hand-moulded knee spacers demonstrated a mean stiffness of 4509 $( \pm 1092.6) \mathrm{N}$ and $1008.7( \pm 275.4) \mathrm{N} / \mathrm{mm}$ respectively. The maximum axial displacement was $1.19 \pm 0.57 \mathrm{~mm}$ and $0.89 \pm 0.30 \mathrm{~mm}$ for specimens implanted with COPAL knee spacers and hand-moulded spacers respectively. The differences between COPAL and hand-moulded knee spacers were not statistically different.

Conclusions: Our study demonstrated that dynamic knee spacers may be able to withstand more than the touch-down load permitted in previous studies, and this may allow more weight-bearing during ambulation. Previous studies have demonstrated that hand-moulded knee spacers have similar advantages to commercially available dynamic spacers with respect to mobility, pain, bone loss, and reinfection rate. Given that ambulation with weight-bearing up to $1200 \mathrm{~N}$ is permitted during rehabilitation, it may be more cost-effective to fabricate hand-moulded spacers in revision total knee arthroplasty.
\end{abstract}

Keywords: Dynamic knee spacers, Hand-mould spacers, Load, Axial displacement, Stiffness

\footnotetext{
* Correspondence: sookyeec@oslomet.no

${ }^{1}$ Department of Orthopaedic Surgery, University Hospital Tuebingen,

Tuebingen, Germany

${ }^{2}$ Faculty of Health Sciences, Oslo Metropolitan University, Oslo, Norway

Full list of author information is available at the end of the article
}

(c) The Author(s). 2019 Open Access This article is distributed under the terms of the Creative Commons Attribution 4.0 International License (http://creativecommons.org/licenses/by/4.0/), which permits unrestricted use, distribution, and reproduction in any medium, provided you give appropriate credit to the original author(s) and the source, provide a link to the Creative Commons license, and indicate if changes were made. The Creative Commons Public Domain Dedication waiver (http://creativecommons.org/publicdomain/zero/1.0/) applies to the data made available in this article, unless otherwise stated. 


\section{Background}

The two-stage revision protocol represents the current gold standard for treating infected total knee replacement implants [1-5]. When an infected prosthesis is first removed, patients will receive an antibiotic-loaded cement spacer. The ideal duration for antibiotic therapy is not defined, but previous studies recommend a six- to twelve-weeks course [6-11]. When the infection is eradicated, a second surgery is performed to remove the spacer and re-implant a revision prosthesis. Muscle loss and soft tissue retraction during the time between procedures are common; they also prolong the second surgical stage and the recovery thereafter.

Dynamic spacers allow some knee movement between procedures, which may facilitate re-implantation and improves the range of motion after second-stage revision surgery [6, 12]. While the advantages of dynamic spacers in the treatment of infected total knee arthroplasty (TKA) have been widely described, there is no agreement about the best type of spacer to be used [13-20]. Dynamic spacers can be fabricated using different moulds, or may be purchased pre-packaged by the manufacturer. It appears the type of spacer implanted does not influence the infection eradication rate in TKA revision for infection; Among the various types of dynamic spacers in use (PROSTALAC, Hofmann technique, cemented moulds, and Spacer-K), control of infection does not appear to differ significantly between manufactured spacers and surgeon-made (or hand-moulded) dynamic spacers [21].

However, to prevent muscle atrophy, allowing early ambulation with weight-bearing between staged procedures will enable early restoration to knee function. With the use of the PROSTALAC antibiotic-loaded spacer (Depuy, Warsaw, IN), patients were allowed weight bearing and motion as tolerated by the joint before reimplantation of a revision prosthesis between 18 weeks and two years. After week eight postoperatively, 95\% of the patients were allowed full weight bearing, without the use of assistive devices $[3,17,22]$. It should be noted that while PROSTALAC is made primarily of antibioticloaded bone cement, the articular surfaces are fabricated with stainless-steel on ultrahigh- molecular-weight polyethylene (PE) [7]. In other studies, full weight bearing was discouraged [23] when articulating components are fabricated only from cement, and cement-covered PEfabricated components.

Commercially available moulds are often used during fabrication of dynamic spacers as they produce significantly smoother surfaces of the articulating parts and are easy to prepare [23-25]. However, the system is considered rather expensive since the moulds are only for single use [7, 26]. A commonly-used and cost-effective alternative is the hand-moulded spacers. They can be fabricated in any operating theatre without specific tools and moulds, and retain most of the advantages of dynamic spacers [27-29]. Another added advantage of hand-moulded spacers includes the possibility of adding higher doses of antibiotic in the bone cement [25, 30]. The main disadvantages of hand-moulded spacers are that they may not have reproducible mechanical characteristics [31], and the spacers are potentially unstable [14] so an extension brace or orthosis have to be worn during ambulation [2, 27, 32].

Since at least six weeks must pass between the two stages and the patient should be encouraged to weightbear on the knee to prevent soft tissue contractures, the mechanical performances of dynamic knee spacers fabricated from bone cement is a key issue. Evaluation of the spacers' ability to withstand loading during the six weeks' rehabilitation period between the two-stage revision, is not yet present in literature. So the main aim in this study, is to biomechanically assess the loading capacity of implanted dynamic knee spacers fabricated from COPAL knee moulds (Heraeus Medical GmbH, Wehrheim, Germany), and compare them with hand-moulded spacers.

\section{Methods}

Cadaveric specimens were purchased from Science Care, Phoenix, Arizona, USA. Ethics for the research protocol, procurement and use of cadaveric specimens were obtained from the ethics committee of the medical faculty of Uniklinik Tuebingen (proj nr: 006/2018B02) in accordance with the Declaration of Helsinki. COPAL bone cement ( $40 \mathrm{~g}$ per packet) impregnated with $1.0 \mathrm{~g}$ of gentamicin and $1.0 \mathrm{~g}$ of clindamycin (Heraeus Medical $\mathrm{GmbH}$, Wehrheim, Germany) were used to fabricate both types of knee spacers. Skin and other soft tissues were first removed. One surgeon prepared all the specimens for implanting of knee prostheses [33]. Thereafter, the prosthesis was removed, taking precaution to ensure minimal bone loss. The dynamic cement spacers were then implanted securely with cement.

\section{COPAL knee spacers}

Seven knees (out of eight) were implanted with COPAL knee spacers fabricated using COPAL knee moulds. The tibial plateau of one specimen was damaged during removal of the prosthesis, so it had to be removed from the study. Mould sizes and height of tibial component were determined by the same surgeon (Figs. 1, 2). One spacer was fabricated for each specimen. The spacer was implanted on the day of testing.

\section{Hand-moulded knee spacers}

Eight knees were implanted with hand-moulded spacers (Figs. 3, 4). All hand-moulded spacers were fabricated and implanted by the same surgeon. The spacer was 


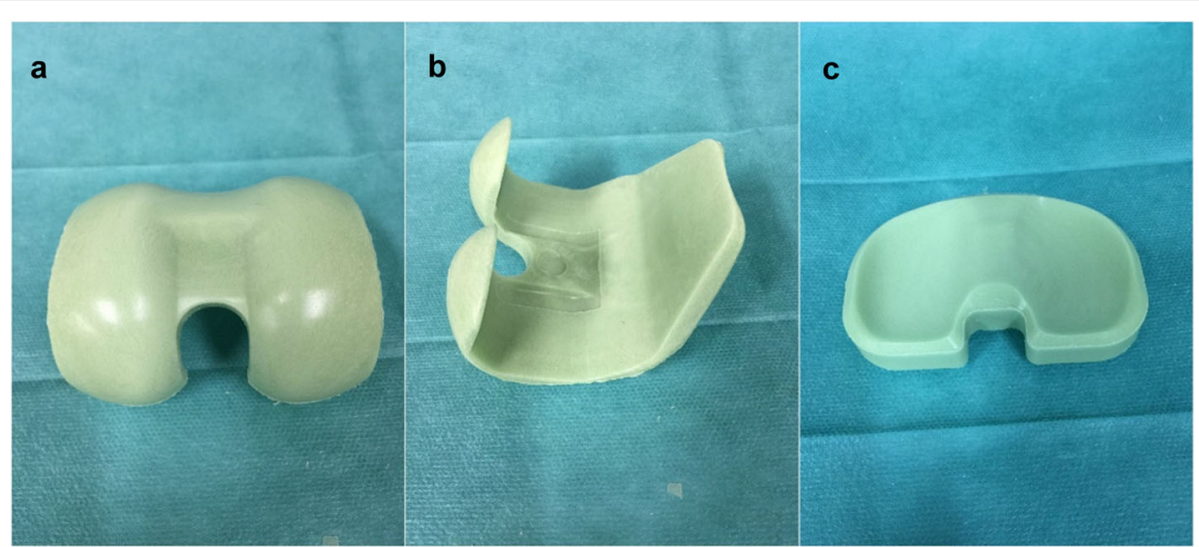

Fig. 1 The femoral $(\mathbf{a}, \mathbf{b})$ and tibial components (c) of the knee spacer fabricated from COPAL knee moulds

fabricated directly onto the specimen and ensured that it adhered strongly to the bone surface. Fabrication was performed on the day of testing. One spacer was fabricated for each specimen. To ensure that the bone cement is completely polymerized, we waited two hours before performing the experiments.

\section{Experiments}

Experiments were performed on the MTS (MTS Systems, MN, USA) testing machine. All tests were performed at room temperature. Radiographic images of each specimen was performed prior testing, to ensure the integrity of the specimens. The femur and tibia ends were embedded and fixed into aluminum cylinders using bone cement. In the femoral clamp, the femur was mounted to a jig which is tilted by six degrees angle with respect to the normal, resembling the physiological valgus [34]. Each knee was placed in ten degrees flexion which was adopted from Wan et al., 2012 [25] since postoperative patients in the Uniklinik Tuebingen were to keep their knees immobilised in extension for six weeks (Fig. 5).

The specimens were subjected to two different loading protocols. In the first protocol, the specimens underwent a single axial loading test. This was to access the mechanical reliability of the spacer in a situation when the patient does not use crutches or any support during rehabilitation. During testing, an axial load was applied with a loading rate of $200 \mathrm{~mm} / \mathrm{min}$ on the knee specimen [35] (Fig. 6). After testing, maximum load and stiffness were determined. Maximum load was defined to be the highest measurable load during the single axial
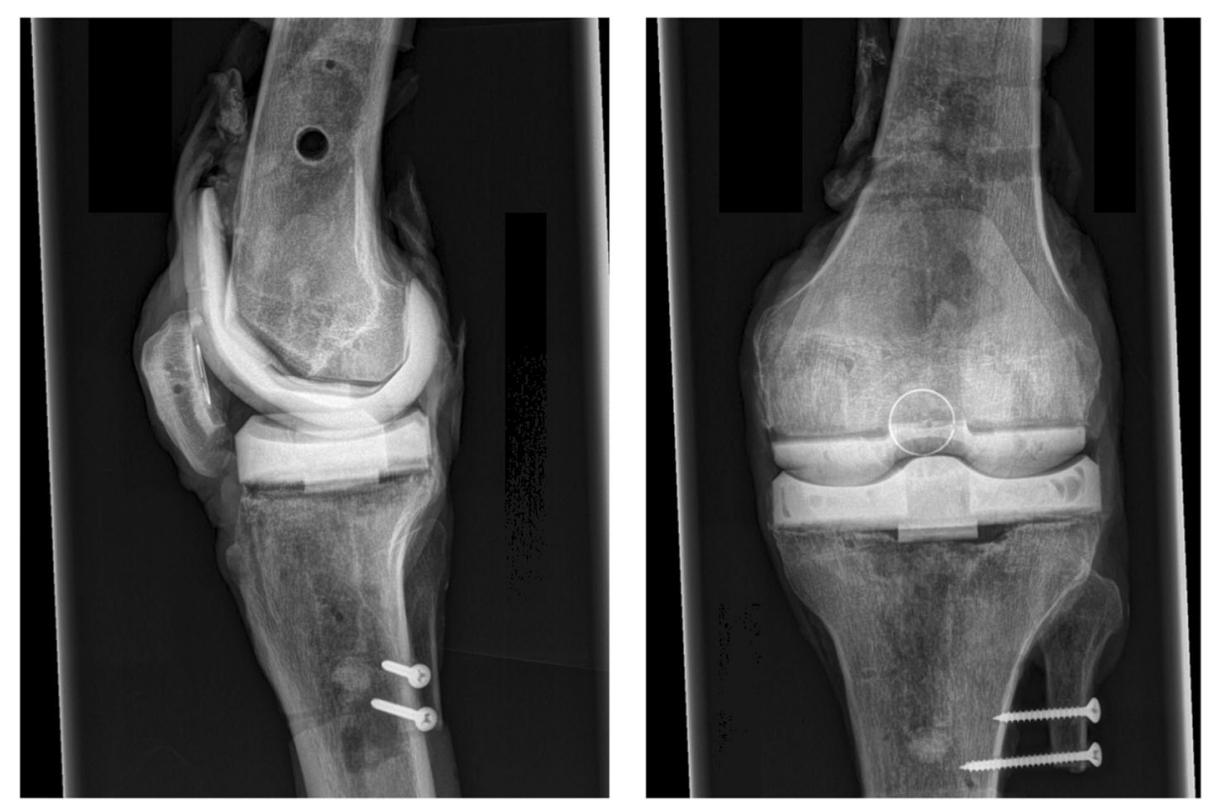

Fig. 2 X-ray of one specimen with COPAL dynamic spacer before testing 


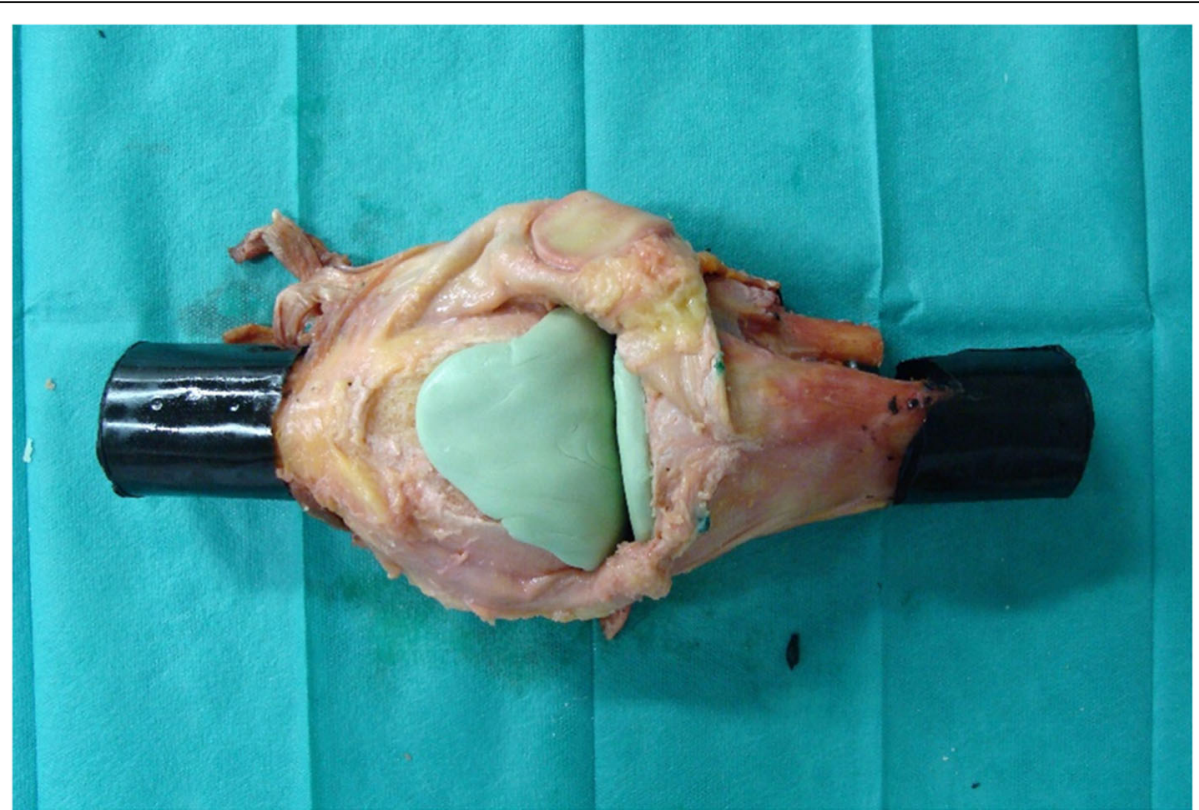

Fig. 3 One knee specimen implanted with hand-moulded spacers

loading test. Stiffness was defined as the gradient of the linear region of the load-displacement curve, determined from least-squares fitting (Fig. 7).

In the second protocol, the specimens underwent a stepwise cyclic loading test, adapted from Weimann et al., 2013 [35]. A preload of $30 \mathrm{~N}$ was first applied. Then, the specimens were cyclically loaded in five steps: $30-400 \mathrm{~N}, 30-600$ $\mathrm{N}, 30-800 \mathrm{~N}, 30-1000 \mathrm{~N}$, and $30-1200 \mathrm{~N}$ (Fig. 8). This protocol represents a reasonable amount of knee loading experienced during rehabilitation [35]. There were $1000 \mathrm{cy}-$ cles in each step. Cyclic loading was performed at a loading frequency of $1.5 \mathrm{~Hz}$; This was the average frequency calculated from the test protocol of $1.3 \mathrm{~Hz}$ suggested by Weimann et al., 2013 [35] and the average walking frequency of $1.8 \mathrm{~Hz}$ reported by Pachi and Ji 2005 [36]. Axial displacement (d) after every 1000th cycle, and changes to the axial displacement $(d)$ at each cycle was also determined. Since contact mechanics at different regions of the knee are affected by
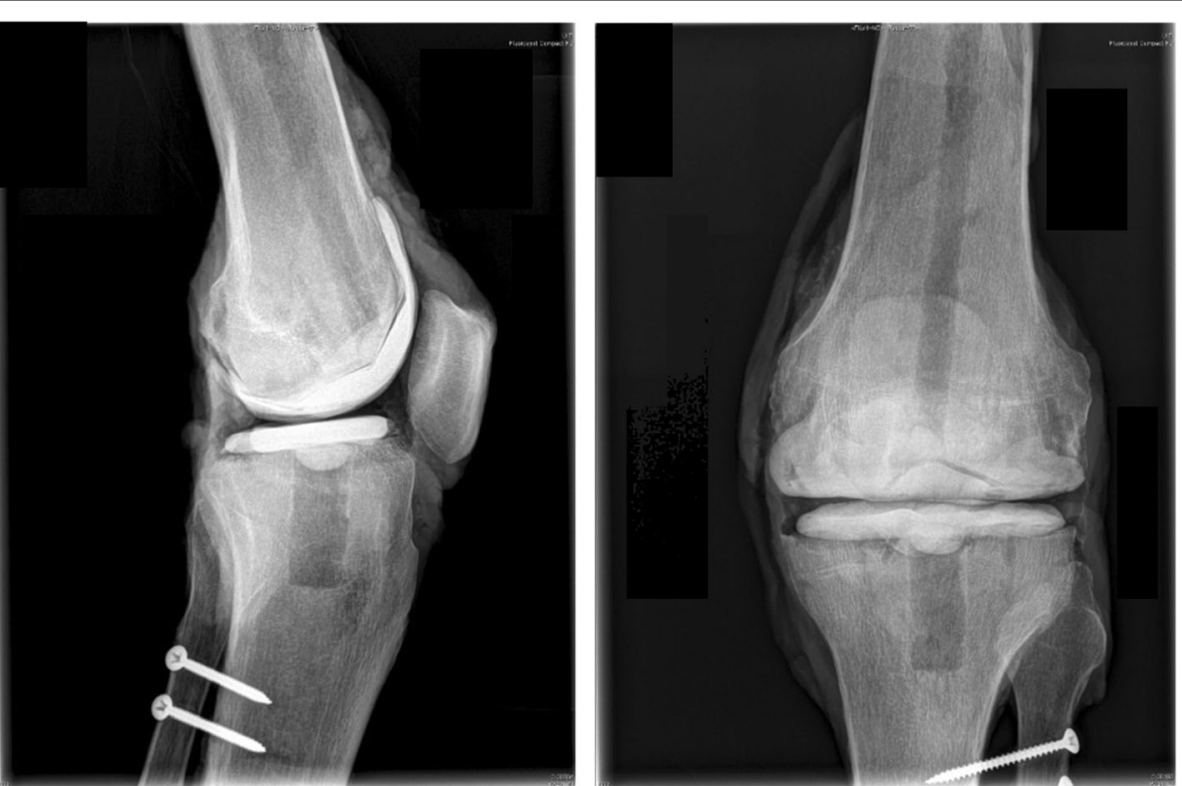

Fig. 4 X-ray of one specimen with hand-moulded dynamic spacer before testing 


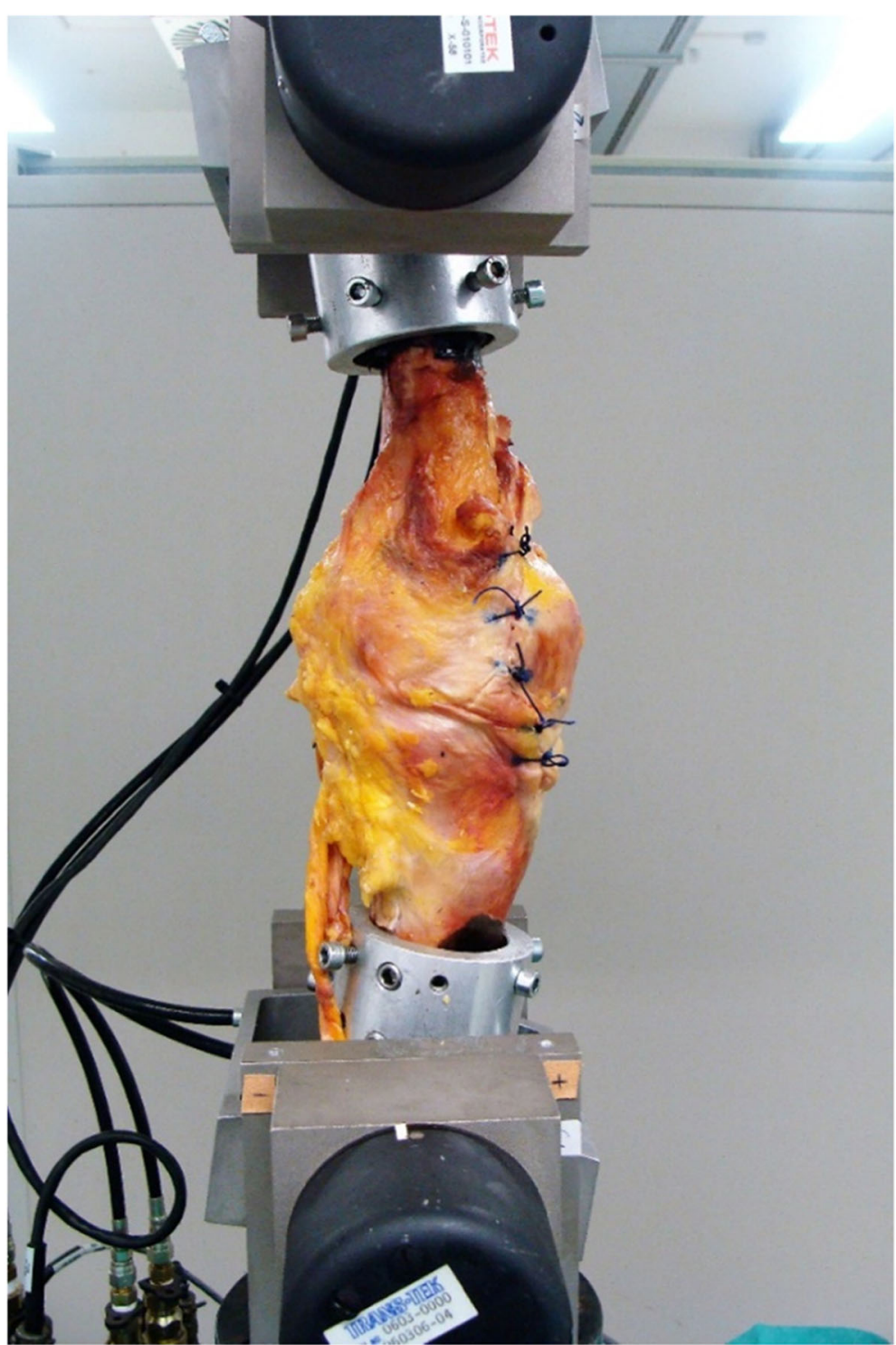

Fig. 5 One knee specimen mounted at 10 degrees flexion between the upper and lower grips of the MTS machine

loading, $d$ would describe the relative translation of the tibia with respect to the femur during applied axial load. After testing, failure was visually monitored by the surgeon and in radiographic images. Results were tested for statistically significant differences (two-tailed, $p<0.05$ ) using an unpaired $\mathrm{t}$ test. Levene's test was used to assess the equality of variances between groups.

\section{Results}

From three specimens implanted with COPAL knee spacers, the result of the axial load-to-failure test showed a maximum load and mean stiffness of $5202( \pm 486.9) \mathrm{N}$ and $1098( \pm 201.5) \mathrm{N} / \mathrm{mm}$ (Table 1). Four specimens implanted with hand-moulded knee spacers, exhibited a maximum load and mean stiffness of $4509( \pm$ 1092.6) N and $1008.7( \pm 275.4) \mathrm{N} / \mathrm{mm}$ respectively (Table 1$)$. Mean difference for maximum load was $692.2( \pm 687.8) \mathrm{N}$ [95\% confidence interval (95\% CI): $-1075.9,2460.4]$. Mean difference for stiffness was $89.6( \pm 189.8) \mathrm{N} / \mathrm{mm}$ [95\% CI: - 398.2, 577.5].

There was a time-dependent axial displacement for all specimens during cyclic loading (Fig. 8). However, changes of axial displacement $(d)$ at every cycle was not significantly different (refer to Additional file 1: Figure. S1). So, axial displacement after every 1000th cycle was represented in Table 2 for both types of knee spacers. The maximum mean displacement of four specimens implanted with COPAL knee spacers after 5000 cycles was $1.19 \pm 0.57 \mathrm{~mm}$ (Table 2). The mean axial displacement was $0.36( \pm 0.14) \mathrm{mm}, 0.63( \pm 0.30) \mathrm{mm}, 0.83( \pm$ 

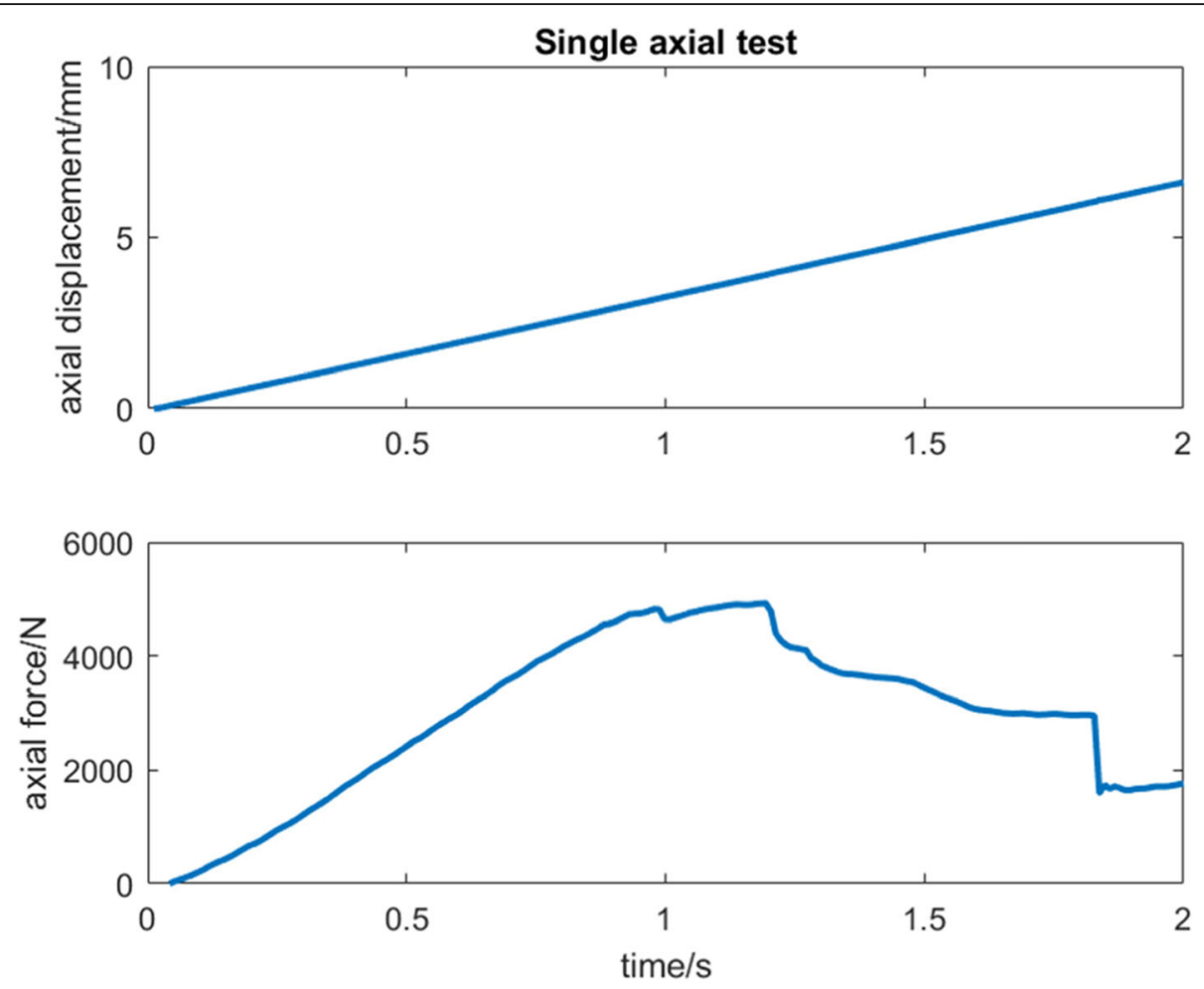

Fig. 6 First protocol where the knee specimen underwent a single axial loading test

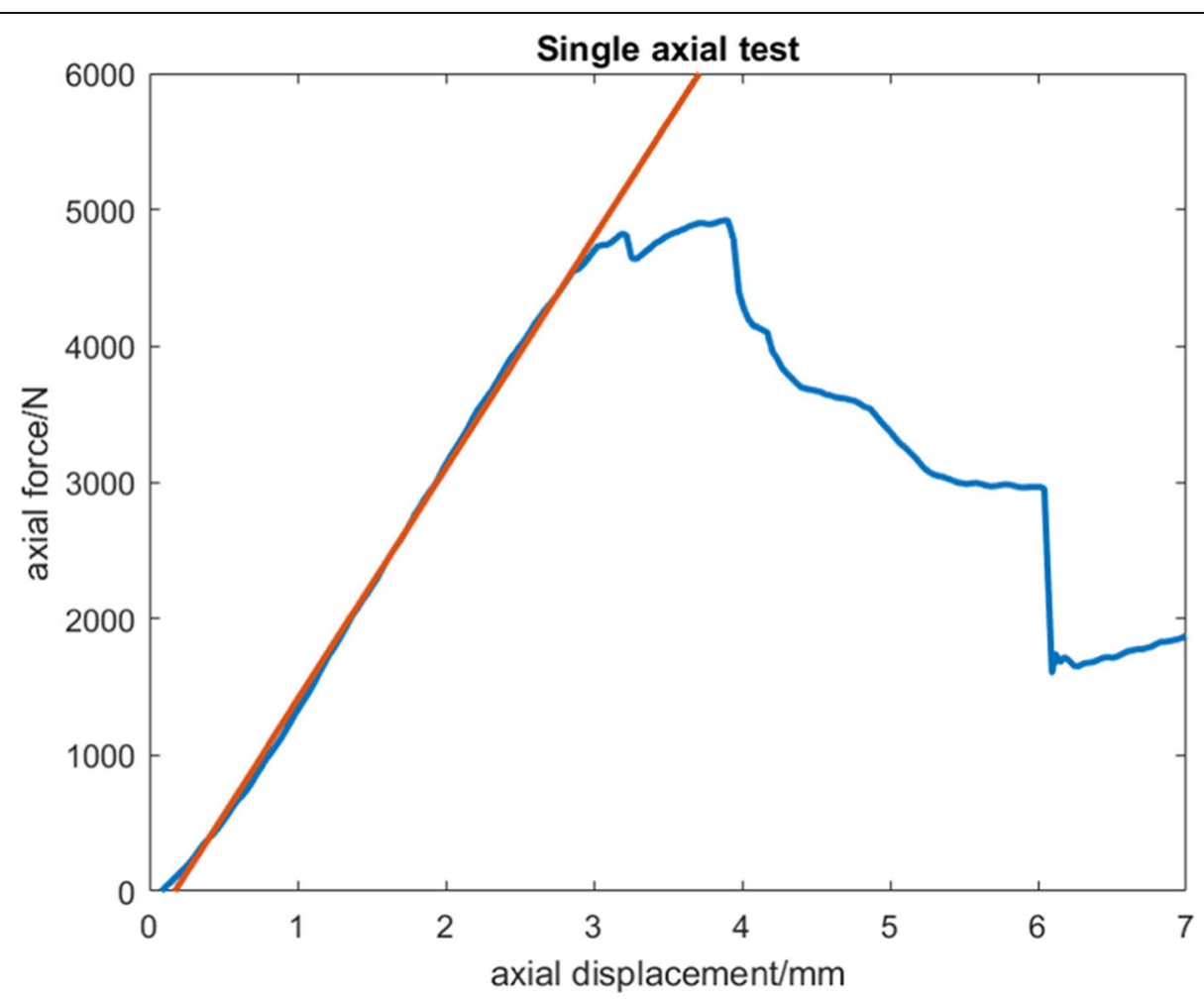

Fig. 7 Load-displacement curve with stiffness calculated from linear gradient (red line) 

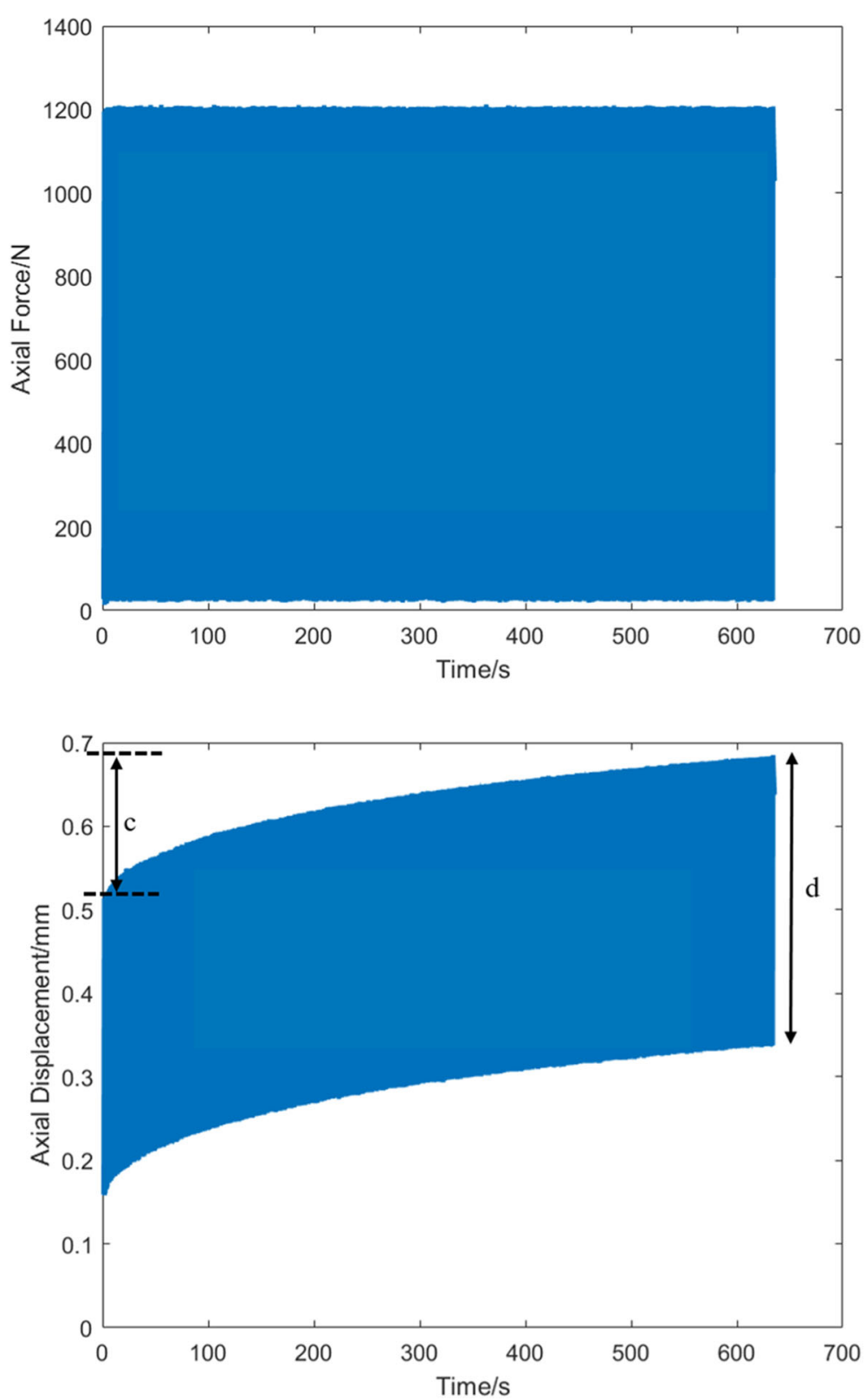

Fig. 8 Axial force (top) and displacement (bottom) of 30-1200 N cyclic loading test of one specimen implanted with COPAL spacer. Axial displacement (d) at the $1000^{\text {th }}$ cycle was determined. $\mathrm{c}$ is the maximum amount of deviation from the first cycle

Table 1 Results of specimens that underwent the axial load-to-failure test, and equality of variance

\begin{tabular}{lllcc}
\hline & \multicolumn{2}{c}{ Mean \pm SD } & & \multicolumn{2}{c}{ variance } \\
\cline { 2 - 5 } & $\operatorname{COPAL}(n=3)$ & hand-moulded $(\mathrm{n}=4)$ & 0.32 & $\mathrm{p}$-value \\
\hline Maximum Load $(\mathrm{N})$ & $5202.0 \pm 486.9$ & $4509.7 \pm 1092.6$ & 0.36 \\
Stiffness $(\mathrm{N} / \mathrm{mm})$ & $1098.3 \pm 201.5$ & $1008.7 \pm 275.4$ & 0.64 & 0.56 \\
\hline
\end{tabular}


Table 2 Results of mean displacement $d$ (in $\mathrm{mm}$ ) of specimens underwent cyclic loading test, and equality of variance

\begin{tabular}{lllll}
\hline & \multicolumn{2}{l}{ Mean \pm SD } & & variance \\
\cline { 2 - 3 } Cyclic load & COPAL $(n=4)$ & hand-moulded $(n=4)$ & $p$-value & $p$-value \\
\hline [30 400] & $0.36 \pm 0.14$ & $0.36 \pm 0.20$ & 0.99 & 0.56 \\
{$\left[\begin{array}{lllll}30 & 600\end{array}\right]$} & $0.63 \pm 0.30$ & $0.48 \pm 0.19$ & 0.42 & 0.33 \\
{$\left[\begin{array}{llll}30 & 800\end{array}\right]$} & $0.83 \pm 0.40$ & $0.65 \pm 0.30$ & 0.48 & 0.67 \\
{$\left[\begin{array}{ll}30 & 1000\end{array}\right]$} & $1.01 \pm 0.44$ & $0.84 \pm 0.43$ & 0.62 & 0.96 \\
{$\left[\begin{array}{lll}30 & 1200\end{array}\right]$} & $1.19 \pm 0.57$ & $0.89 \pm 0.30$ & 0.36 & 0.26 \\
\hline
\end{tabular}

$0.40) \mathrm{mm}, 1.01( \pm 0.44) \mathrm{mm}$, and $1.19( \pm 0.57) \mathrm{mm}$, with cyclic loading forces ranging from $30 \mathrm{~N}$ to $400 \mathrm{~N}, 30 \mathrm{~N}$ to $600 \mathrm{~N}, 30 \mathrm{~N}$ to $800 \mathrm{~N}, 30 \mathrm{~N}$ to $1000 \mathrm{~N}$, and $30 \mathrm{~N}$ to $1200 \mathrm{~N}$ respectively. There was a mean of $0.19( \pm 0.04)$ $\mathrm{mm}$ increase with every additional load of $200 \mathrm{~N}$.

The maximum mean displacement of four specimens implanted with hand-moulded knee spacers after 5000 cycles was found to be $0.89 \pm 0.30 \mathrm{~mm}$ (Table 2). The mean axial displacement was $0.36( \pm 0.20) \mathrm{mm}, 0.48( \pm$ $0.19) \mathrm{mm}, 0.65( \pm 0.30) \mathrm{mm}, 0.84( \pm 0.43) \mathrm{mm}$, and 0.89 $( \pm 0.30) \mathrm{mm}$, with cyclic loading forces ranging from 30 $\mathrm{N}$ to $400 \mathrm{~N}, 30 \mathrm{~N}$ to $600 \mathrm{~N}, 30 \mathrm{~N}$ to $800 \mathrm{~N}, 30 \mathrm{~N}$ to 1000 $\mathrm{N}$, and $30 \mathrm{~N}$ to $1200 \mathrm{~N}$ respectively. There was a mean of $0.13( \pm 0.08) \mathrm{mm}$ increase with every additional load of $200 \mathrm{~N}$

\section{Discussion}

During the tests, the tibia was fixed in the MTS machine, which did not represent physiological conditions during knee loading. While the testing protocol of the single axial and cyclic loading in this study may not reflect the complexity of in-vivo loading occurring at the knee joint, applications of these simple loading patterns can provide an insight into possible spacer failure during repetitive loading. In addition, only compression tests were performed in this study. Mechanical characteristics may be different in other loading modes. Transverse loading or side load capacity was not considered in this study, though it is usually smaller than the normal axial load capacity [37].

It should be noted that the highest measurable load and stiffness were determined in-vitro, without any active muscle forces and passive soft tissues. A higher joint compressive load will be expected when muscle forces act to control joint motion during translation and rotation. The load sharing properties between muscles and ligaments will also provide the knee its stability at a higher load. In this study, no significant differences were found in the highest measurable load (Table 1) though the spacers were dislodged after the single axial loading test. Loosening of the spacers would be considered a failure since this would require another surgery. The exact load at which the spacers were dislodged is unknown in this study. No significant differences were also found in the stiffness during the single axial loading test (Table 1). While the COPAL spacers were fabricated from moulds, the hand-moulded spacers were custommade and dependent on the surgeon, which may result in a wider standard deviation. Since both COPAL and hand-moulded spacers were fabricated from the same material, variability in stiffness may also be due to differences between the specimens and attachment at the spacer-bone interface. During the single axial loading test, the spacers were not broken but dislodged from the knee joints. In other words, the spacer may not have reached its fracture point, but there was a failure to transfer loading between the spacer and the bone when an axial load was applied. Nevertheless, we acknowledge that a report of no significance differences in our study could be a Type 2 error.

Novitskaya et al., 2014 [38] found that compressive creep loading of bone samples at the proximal tibia resulted in bending of the trabecular bone, leading to permanent deformation. We postulated that the timedependent response in the axial displacement may be a result of creep behaviour of the trabecular bone. Since the axial displacement is small $(d<2 \mathrm{~mm}, c=0.22 \pm 0.21$ $\mathrm{mm}$ ) (Fig. 8), it has not affected implant alignment [38], and has not resulted in loosening of the spacer. However, prolonged testing at higher loads may lead to loosening of the spacer, previously found in hip implants $[39,40]$,

Axial displacement in this study (Table 2) was larger than the $0.6-1.2 \mathrm{~mm}$ reported in intact knees [41], but within $0.98-3.10 \mathrm{~mm}$ in meniscectomized knees during compression loading up to $1000 \mathrm{~N}$ [42-44]. The wider range reported in meniscectomized knees could be due to differences of the joints tested or in the experimental setups. In this study, there were no signs of failure for both COPAL and hand-moulded spacers as determined visually by the orthopaedic surgeon, and no structural damage was found in radiographic images. The knee spacers were not dislodged from the knee joints, nor were they broken. So both COPAL and hand-moulded knee spacers could withstand weight-loading up to 1200 N. Nevertheless, we acknowledge that the absence of any visible damage or signs of failure during the cyclic loading test, is not necessarily related to permanent damage at the knee joint. There may be other damage to bone and soft tissues during in-vivo loading.

Few studies on dynamic knee spacers have reported the allowable loading capacity of these spacers. MacAvoy et al., 2005 [45] permitted full weight-bearing with the use of crutches or walker during ambulation with a hinged knee brace. Other studies allowed touch-down or partial weight bearing, but no more information was provided [1, 4, 7, 20, 23, 24, 46-51]. Hofmann et al., 
1995 [52] and Hofmann et al., 2005 [22] allowed 50\% of body weight on the affected knee with the use of crutches or a walker. Wan et al., 2012 [25] encouraged the patients to gently load bear to $312 \mathrm{~N}$. Kohl et al., 2011 [26] instructed the patients to partial weight bear to $20 \mathrm{~kg}(196 \mathrm{~N}) 48 \mathrm{~h}$ after surgery. Our study demonstrated that both types of dynamic spacers may be able to withstand more than the touch-down load previously allowed in other studies, and this may permit more weight-bearing during ambulation for patients during the six weeks of rehabilitation.

A patient's ability to bend the knee increases his or her quality of life between stages [4], especially if a long period of antibiotic therapy is necessary to eradicate the infection. In this study, the knee specimens were kept at an angle of $10^{\circ}$ [25] during cyclic loading after consultation with the surgeon; When a dynamic spacer is implanted, patients in the Orthopaedics department in Uniklinikum Tuebingen kept their knees in an immobilizer in full extension for six weeks prior to the second-stage operation. Previous studies suggested a continuous passive motion (CPM) limited to $90^{\circ}$ of flexion for patients after the first stage knee replacement surgeries, and revision surgeries [23, 32, 46, 50-52], to enable continued mobilization of soft tissues and the prevention of contractures. In this study, CPM was not considered. Accordingly, in our study, we cannot compare the allowable range of motion nor the loading capacity at different knee angles of both COPAL knee spacers and the hand-moulded knee spacers. Nevertheless, a comparable range of motion up to $104^{\circ}-107^{\circ}$ was reported in previous studies $[27,50,52,53]$.

To ensure consistency, only one surgeon fabricated all preformed and hand-moulded spacers in this study. However in the clinics, the preparation of hand-moulded spacers can be custom-made by different surgeons, resulting in varied mechanical characteristics [31]. Other factors such as the surgeon's experience with the fabrication of spacers and the amount of bone loss and scar tissue, will contribute to the successful outcome in using a spacer. So, the utilisation of one surgeon in this study is a limitation in extending these results to clinical practice. This research is also limited by a small sample size. We are compelled to restrict the sampling size due to limited availability of cadaveric specimens. In addition, specimens, which were examined clinically by the surgeon and in radiographs, were excluded if any degeneration and deformities were observed.

One major failure mechanism is loosening of the spacer due to loss of fixation at the spacer-bone interface. Since one possible cause of this loosening is dependent on the applied load [38], cyclic loading was increased step-wise to $1200 \mathrm{~N}$. This maximum load was chosen after considering that the patient will be walking with the aid of crutches during rehabilitation. However, another limitation of this study is not cyclically loading the knee spacers to failure, which follows previous advice that full weight bearing should be discouraged [10, 23]. While knee spacers can also be fabricated with metal or $\mathrm{PE}$ articulating surfaces to enable a higher loading capacity, it should be emphasized that the main aim of a spacer is the eradication of infection. Metal and PE surfaces have no antibiotic protection, and thus, have the potential for re-infection [2, 20,31]. In a pilot test, the femoral component in both the COPAL knee spacer and hand-moulded spacer loosened or broke (refer to Additional file 1: Figure. S2) when cyclic loading was performed at $2600 \mathrm{~N}$. Further study focusing on fatigue loading of the knee spacers is envisioned, considering that cement spacers may exhibit abrasive wear after a few weeks $[16,54,55]$.

\section{Conclusion}

It has been argued that while the COPAL knee spacer is expensive and discarded after six weeks, expenses from a prolonged hospitalisation due to immobilisation and complications are significantly more. Savings from an earlier discharge from hospital can outweigh the increased cost of the use of the moulding system [17]. So far, hand-moulded knee spacers have similar advantages to commercially available dynamic spacers with respect to mobility, pain, bone loss, and reinfection rate $[28,50$, $53,56]$. In this study, we have also demonstrated that the loading capacity between COPAL and handmoulded knee spacers were not statistically different. However, given the small sample size, we nevertheless acknowledge the possibility of a Type 2 error. Given that ambulation with weight-bearing up to $1200 \mathrm{~N}$ is permitted during rehabilitation, it may be more cost-effective to utilise hand-moulded spacers in revision total knee arthroplasty.

\section{Supplementary information}

Supplementary information accompanies this paper at https://doi.org/10. 1186/s12891-019-2982-5.

\section{Additional file 1: Figure S1. Mean and standard deviation of changes in axial displacement (d) during cyclic loading [30 $1200 \mathrm{~N}$ ] of all specimens implanted with COPAL knee spacers. Figure S2. Broken femoral component of COPAL knee spacer of one specimen during cyclic loading to $2600 \mathrm{~N}$}

\section{Abbreviations}

CPM: Continuous passive motion; PE: Ultrahigh- molecular-weight polyethylene; SD: Standard deviation; TKA: Total knee arthroplasty

\section{Acknowledgements}

We acknowledge Dr. Andrea Lorenz for the conceptualisation and the acquisition of funding for this study. 


\section{Authors' contributions}

SYC and SF developed the study design. SF performed the fabrication and implantation of spacers. SYC and LS carried out the biomechanical studies. SYC performed the data analysis and statistical evaluation. SYC drafted the manuscript. All authors read and approved the manuscript.

\section{Funding}

Funding received came from Stiftung Endoprothetik (proj nr. S02/17). The funders had no role in study design, data collection and analysis, decision to publish, and preparation of the manuscript.

\section{Availability of data and materials}

All relevant data are within the manuscript, tables and its supplementary files. Data of human subjects are available from the University Hospital Tübingen for researchers who meet the criteria for access to confidential data, as stated in the ethics approval by the University Hospital Tübingen (project nr: 006/2018B02).

\section{Ethics approval and consent to participate}

Ethics for the research protocol and use of cadaveric specimens were obtained from the ethics committee of the medical faculty of Uniklinik Tuebingen (proj nr: 006/2018B02).

\section{Consent for publication}

Not Applicable.

\section{Competing interests}

The authors declare that they have no competing interests.

\section{Author details}

'Department of Orthopaedic Surgery, University Hospital Tuebingen, Tuebingen, Germany. ${ }^{2}$ Faculty of Health Sciences, Oslo Metropolitan University, Oslo, Norway. ${ }^{3}$ Institute of Applied Mechanics, University of Stuttgart, Stuttgart, Germany.

\section{Received: 23 May 2019 Accepted: 29 November 2019}

Published online: 21 December 2019

\section{References}

1. Ocguder A, Firat A, Tecimel O. Two-stage total infected knee arthroplasty treatment with articulating cement spacer. Arch Orthop Trauma Surg. 2010: 719-25.

2. Shen $H$, Zhang $X$, Jiang $Y$, Wang $Q$, Chen $Y$, Wang $Q$, et al. Intraoperativelymade cement-on-cement antibiotic-loaded articulating spacer for infected total knee arthroplasty. Knee. 2010;17(6):407-11 https://doi.org/10.1016/j. knee.2009.11.007.

3. Gooding CR, Masri BA, Duncan CP, Greidanus NV, Garbuz DS. Durable infection control and function with the PROSTALAC spacer in two-stage revision for infected knee Arthroplasty. Clin Orthop Relat Res. 2011;469: 985-93

4. Castelli CC, Gotti V, Ferrari R. Two-stage treatment of infected total knee arthroplasty: two to thirteen year experience using an articulating preformed spacer. Int Orthop. 2014;38:405-12

5. Charette RS, Melnic CM. Two-stage revision Arthroplasty for the treatment of prosthetic joint infection. Curr Rev Musculoskelet Med. 2018;11(3):332-40

6. Emerson RH, Muncie M, Tarbox TR, Higgins LL. Comparison of a static with a mobile spacer in total knee infection. Clin Orthop Relat Res. 2002:404:132-8.

7. Cuckler JM. The infected total knee: management options. J Arthroplast. 2005:20(S2):33-6.

8. Whittaker JP, Warren RE, Jones RS, Gregson PA. Is prolonged systemic antibiotic treatment essential in two-stage revision hip replacement for chronic Gram-positive infection? J Bone Joint Surg Br. 2009;91-B(1):44-51. https://doi.org/10.1302/0301-620X.91B1.20930.

9. Bernard L, Legout L, Zürcher-Pfund L, Stern R, Rohner P, Peter R, et al. Six weeks of antibiotic treatment is sufficient following surgery for septic arthroplasty. J Inf Secur. 2010;61(2):125-32

10. Johnson AJ, Sayeed SA, Naziri Q, Khanuja HS, Mont MA. Minimizing dynamic knee spacer complications in infected revision arthroplasty. Clin Orthop Relat Res. 2012:470(1):220-7.
11. Dubée $V$, Zeller V, Lhotellier L, Kitzis MD, Ziza JM, Mamoudy P, et al. Continuous high-dose vancomycin combination therapy for methicillinresistant staphylococcal prosthetic hip infection: a prospective cohort study. Clin Microbiol Infect. 2013;19(2):E98-E105.

12. Chiang ER, Su YP, Chen TH, Chiu FY, Chen WM. Comparison of articulating and static spacers regarding infection with resistant organisms in total knee arthroplasty. Acta Orthop. 2011;82(4):460-4.

13. Booth REJ, Lotke PA. The results of spacer block technique in revision of infected total knee arthroplasty. Clin Orthop Relat Res. 1989;248:57-60.

14. McPherson EJ, Lewonowski K, Dorr LD. Techniques in arthroplasty. Use of an articulated PMMA spacer in the infected total knee arthroplasty. J Arthroplast. 1995;10(1):87-9.

15. Calton TF, Fehring TK, Griffin WL. Bone loss associated with the use of spacer blocks in infected total knee arthroplasty. Clin Orthop Relat Res. 1997;345:148-54.

16. Fehring TK, Odum S, Calton TF, Mason JB. Articulating versus static spacers in revision total knee arthroplasty for sepsis. Ranawat Award Clin Orthop Relat Res. 2000;380:9-16

17. Haddad FS, Masri BA, Campbell D, Mcgraw RW, Beauchamp CP, Duncan CP. The PROSTALAC functional spacer in two-stage revision for infected knee replacements. J Bone Joint Surg Br. 2000:82-B:807-12. https://doi.org/10. 1302/0301-620x.82b6.10486

18. Siebel T, Kelm J, Porsch M, Regitz T, Neumann WH. Two-stage exchange of infected knee arthroplasty with an prosthesis-like interim cement spacer Acta Orthop Belg. 2002;68(2):150-6.

19. Haleem AA, Berry DJ, Hanssen AD. Mid-term to long-term Followup of twostage Reimplantation for infected Total knee Arthroplasty. Clin Orthop Relat Res. 2004:428:35-9.

20. Choi HR, Malchau H. Are Prosthetic Spacers Safe to Use in 2-Stage Treatment for Infected Total Knee Arthroplasty? J Arthroplasty. 2012;27(8): 1474-9 e1. https://doi.org/10.1016/j.arth.2012.02.023.

21. Mazzucchelli L, Rosso F, Marmotti A, Bonasia DE, Bruzzone M, Rossi R. The use of spacers (static and mobile) in infection knee arthroplasty. Curr Rev Musculoskelet Med. 2015:8:373-82

22. Hofmann AA, Goldberg T, Tanner AM, Kurtin SM. Treatment of infected Total knee Arthroplasty using an articulating spacer. Clin Orthop Relat Res. 2005;430:125-31.

23. Evans RP. Successful treatment of total hip and knee infection with articulating antibiotic components: a modified treatment method. Clin Orthop Relat Res. 2004:427:37-46.

24. Durbhakula SM, Czajka J, Fuchs MD, Uhl RL. Antibiotic-loaded articulating cement spacer in the 2-stage exchange of infected total knee arthroplasty. Arthroplast. 2004;19(6):768-74

25. Wan Z, Momaya A, Karim A, Incavo SJ, Mathis KB. Preformed articulating knee spacers in 2-stage Total knee revision Arthroplasty. Minimum 2-year follow-up. J Arthroplast. 2012;27(8):1469-73 https://doi.org/10.1016/j.arth. 2012.01.027.

26. Kohl S, Evangelopoulos DS, Kohlhof H, Krueger A, Hartel M, Roeder C, et al. An intraoperatively moulded PMMA prostheses like spacer for two-stage revision of infected total knee arthroplasty. Knee. 2011;18(6):464-9 https:// doi.org/10.1016/j.knee.2010.09.002.

27. Ha CW. A technique for intraoperative construction of antibiotic spacers Clin Orthop Relat Res. 2006:445:204-9.

28. Pascale V, Pascale W. Custom-made Articulating Spacer in Two-stage Revision Total Knee Arthroplasty. An Early Follow-up of 14 Cases of at Least 1 Year After Surgery. HSS J. 2007;14:159-63.

29. Su Y, Lee OK, Chen W, Chen T. A facile technique to make articulating spacers for infected Total knee Arthroplasty. J Chinese Med Assoc. 2009; 72(3):138-45 https://doi.org/10.1016/S1726-4901(09)70039-5.

30. Alt V, Bechert $T$, Steinrücke $P$, Wagener $M$, Seidel $P$, Dingeldein $E$, et al. An in vitro assessment of the antibacterial properties and cytotoxicity of nanoparticulate silver bone cement. Biomater. 2003:25(18):4383-91.

31. Pitto RP, Spika IA. Antibiotic-loaded bone cement spacers in two-stage management of infected total knee arthroplasty. Int Orthop. 2004:28:129-33.

32. Villanueva M, Ríos A, Pereiro J, Chana F, Fahandez-saddi H. Hand-made articulating spacers for infected total knee arthroplasty : a technical note hand-made articulating spacers for infected total knee arthroplasty a technical note. Acta Orthop. 2006:77(2):329-32.

33. Varacallo M, Johanson NA. Total knee Arthroplasty (TKA) techniques. Treasure Island (FL): StatPearls Publishing LLC; 2018. https://www.ncbi.nlm. nih.gov/books/NBK499896/ 
34. Kapandji IA. Funktionelle Anatomie der Gelenke. Schematisierte und kommentierte Zeichnungen zur menschli-chen Biomechanik. einbändige Ausgabe - obere Extremität, untere Extremität, Rumpf und Wirbelsäu-le. Thieme, Stuttgart and. N Y. 2009.

35. Weimann A, Heinkele T, Herbort M, Schliemann B, Petersen W, Raschke MJ. Minimally invasive reconstruction of lateral tibial plateau fractures using the jail technique: a biomechanical study. BMC Musculoskelet Disord. 2013;14(1): 120 https://doi.org/10.1186/1471-2474-14-120.

36. Pachi A, Ji T. Frequency and velocity of people walking. Struct Eng. 2005;83:36-40.

37. Bergmann G, Bender A, Graichen F, Dymke J, Rohlmann A, Trepczynski A, et al. Standardized loads acting in knee implants. PLoS One. 2014;9(1):1-12 https://doi.org/10.1371/journal.pone.0086035.

38. Novitskaya E, Zin C, Chang N, Cory E, Chen P, D'Lima D, et al. Creep of trabecular bone from the human proximal tibia. Mater Sci Eng C Mater Biol Appl. 2014;40:219-27.

39. Zilch H, Rohlmann A, Bergmann G, Kölbel R. Material properties of femoral cancellous bone in axial loading. Arch Orthop Trauma Surg. 1980;97(4):25762 https://doi.org/10.1007/BF00380706.

40. Schoenfeld CM, Lautenschlager EP, Meyer PRJ. Mechanical properties of human cancellous bone in the femoral head. Med Biol Eng. 1974;12(3):313-7.

41. Kazemi M, Li L. A viscoelastic poromechanical model of the knee joint in large compression. Med Eng Phys. 2014;36.

42. Shrive NG, O'Connor JJ, Goodfellow JW. Load-bearing in the knee joint. Clin Orthop Relat Res. 1978;131:279-87.

43. Kurosawa H, Fukubayashi T, Nakajima H. Load-bearing mode of the knee joint: physical behavior of the knee joint with or without menisci. Clin Orthop Relat Res. 1980;149:283-90.

44. Bendjaballah MZ, Shirazi-Adl A, Zukor DJ. Biomechanics of the human knee joint in compression: reconstruction, mesh generation and finite element analysis. Knee. 1995;2(2):69-79 http://www.sciencedirect.com/science/article/ pii/096801609500018K

45. MacAvoy MC, Ries MD. The ball and socket articulating spacer for infected total knee arthroplasty. J Arthroplast. 2005;20(6):757-62.

46. Van Thiel GS, Berend KR, Klein GR, Gordon AC, Lombardi AV, Della Valle CJ. Intraoperative molds to create an articulating spacer for the infected knee arthroplasty. Clin Orthop Relat Res. 2011:469:994-1001.

47. Kalore NV, Maheshwari A, Sharma A, Cheng E, Gioe TJ. Is there a preferred articulating spacer technique for infected knee Arthroplasty ? Clin Orthop Relat Res. 2012;470:228-35.

48. McPherson E. J; Lewonowski, K; Lawrence DD. Brief communication techniques in Arthroplasty use of an articulated PMMA spacer in the infected Total knee Arthroplasty. J Arthroplast. 1995;10(1):87-9.

49. Pitto RP, Castelli CC, Ferrari R, Munro J. Pre-formed articulating knee spacer in two-stage revision for the infected total knee arthroplasty. Int Orthop. 2005;29(5):305-8.

50. Villanueva-Martínez M, Ríos-Luna A, Pereiro J, Fahandez-Saddi H, Villamor A Hand-made articulating spacers in two-stage revision for infected total knee arthroplasty: good outcome in 30 patients. Acta Orthop. 2008;79(5):674-82.

51. Anderson JA, Sculco PK, Heitkemper S, Mayman DJ, Bostrom MP, Sculco TP. An articulating spacer to treat and mobilize patients with infected Total knee Arthroplasty. J Arthroplast. 2009;24(4):631-5 https://doi.org/10.1016/j. arth.2008.04.003.

52. Hofmann AA, Kane KR, Tkach TK, Plaster RL, Camargo MP. Treatment of infected Total knee Arthroplasty using an articulating spacer. Clin Orthop Relat Res. 1995:321:45-54.

53. Jämsen $E$, Sheng $P$, Halonen $P$, Lehto MUK, Moilanen T, Pajamäki J, et al. Spacer prostheses in two-stage revision of infected knee arthroplasty. Int Orthop. 2006;30:257-61.

54. Villa T, Carnelli D. Experimental evaluation of the biomechanical performances of a PMMA-based knee spacer. Knee. 2007;14(2):145-53.

55. Fink B, Rechtenbach A, Büchner H, Vogt S, Hahn M. Articulating spacers used in two-stage revision of infected hip and knee prostheses abrade with time. Clin Orthop Relat Res. 2011;469(4):1095-102.

56. Hsu YC, Cheng HC, Ng TP, Chiu KY. Antibiotic-loaded cement articulating spacer for 2-stage Reimplantation in infected Total knee Arthroplasty a simple and economic method. J Arthroplast. 2007;22(7):1060-6.

\section{Publisher's Note}

Springer Nature remains neutral with regard to jurisdictional claims in published maps and institutional affiliations.

Ready to submit your research? Choose BMC and benefit from:

- fast, convenient online submission

- thorough peer review by experienced researchers in your field

- rapid publication on acceptance

- support for research data, including large and complex data types

- gold Open Access which fosters wider collaboration and increased citations

- maximum visibility for your research: over $100 \mathrm{M}$ website views per year

At $\mathrm{BMC}$, research is always in progress.

Learn more biomedcentral.com/submissions 